14. Бондаревская Е.В. Ценностные основания личностно ориентированного воспитания // Педагогика. 2007. № 8. C. 44-53.

15. Плигин А.А. Личностно ориентированное образование: история и практика: монография. М.: КСП+, 2003. $432 \mathrm{c}$.

16. Плигин А.А. От индивидуализации обучения к личностно ориентированному образованию // Психология обучения. 2009. № 2. С. 20-30.

17. Лукьянова М.И. Личностно ориентированное образование и готовность к нему педагога // Школьные технологии. 2013. № 1. С. 69-75.

18. Смолеусова Т.В. Концепция личностно ориентированного подхода в образовании на основе проявления личности // Вестник Новосибирского государственного педагогического университета. 2016. № 6 (34). C. 7-16.

19. Трубина Г.Ф. Современные концепции личностно ориентированного образования // Педагогическое образование в России. 2014. № 9. С. 165-169.

20. Разин А.В. Этика: учебник для вузов. М.: Академический проект, 2003. 624 c.

21. Титаренко А.И. Сущность, структура и функции морали // Марксистская этика. М.: Политиздат, 1980. C. $96-133$.

22. Дробницкий О.Г. Проблемы нравственности. М.: Наука, 1977. 334 с.

23. Позднякова О.К. Нравственное сознание учителя: структура и особенности // Инновационное развитие профессионального образования. 2012. № 1 (01). C. $160-166$.

\title{
DEVELOPMENT OF PERSONAL FORMS OF STUDENTS' MORAL CONSCIOUSNESS AS AN IDEA OF PERSONALLY ORIENTED EDUCATION
}

(C) 2017

Tsepkova Anzhelika Nicolaevna, candidate of pedagogical sciences, associate professor of Humanities and Social Sciences Department

Samara Institute - Higher School of Privatization and Entrepreneurship (Samara, Russian Federation)

Abstract. The paper justifies that a personally oriented educational model is one of the ways of solving a problem of student's personality development. The author explains the reasons for the declarative nature of personally oriented education in modern schools: classical foundations of the traditional educational paradigm, transformation of education into service and incorrect understanding of personally oriented education by teachers. The author reveals the role of future teachers' orientation on implementation of personally oriented education. The author considers development of personal forms of students' moral consciousness as an idea of personally oriented education. Special value of consciousness personal forms is proved. The author shows that specific personal forms of teachers' moral consciousness can be presented as personal forms of students' moral consciousness. The paper contains the essence of personal forms of students' moral consciousness. Such personal forms of moral consciousness as kindness, dignity, mercy, responsibility, etc. are necessary for a student to build value judgments as well as for assessment which is the starting point for the spiritual and practical mastering of the world.

Keywords: student; teacher; prospective teacher; personality; personally oriented education; idea; personal form; moral consciousness; evaluation; development; essence; spiritual mastery of world by schoolchild in morality; moral requirement.

\section{АЛГОРИТМ УПРАВЛЕНИЯ \\ ОЗДОРОВИТЕЛЬНО-КОРРИГИРУЮЩЕЙ ДЕЯТЕЛЬНОСТЬЮ ПЕДАГОГОВ В СВЯЗИ С УЧЕБНОЙ РАБОТОЙ ОБУЧАЮЩИХСЯ С КОМПЬЮТЕРОМ}

(C) 2017

Щербакова Наталья Борисовна, старший преподаватель центра дистанционного обучения Нижегородский институт развития образования (2. Нижний Новгород, Российская Федераџия)

Аннотация. Автор статьи актуализирует внимание на проблеме безопасного использования компьютера обучающимися. Отмечено, что взаимодействие школьников с компьютером сопряжено, в первую очередь, с воздействием на их здоровье таких негативных факторов, как зрительное, психическое и физическое напряжения, связанные с длительным статическим напряжением мышц пользователя персонального компьютера. В связи с этим особое значение приобретает повышение готовности педагогов к оздоровительно-корригирующей деятельности при организации работы обучающихся с компьютером. Автор выделяет следующие компоненты оздоровительно-корригирующей деятельности педагога: субъект, объект, средства, процесс, результат, среда, условия. Сформулировано базовое определение управления оздоровительно-корригирующей деятельностью педагогов. Представлен алгоритм управления здоровьеобеспечивающей деятельностью педагогов, этапы которой определены в соответствии со следующими функциями управления: проектированием, включающим в себя распределение целей и средств в пространстве (последовательность) и времени (продолжительность); организацией, представляющей собой упорядочение действий в пространстве и времени; регулированием как субординацией, координацией и коррекцией действий; контролем и учетом, суть которых состоит в сличении цели и результата, а также в фиксации и определении меры в пространстве и времени.

Ключевые слова: здоровье обучающихся; деятельность здоровьеобеспечения; готовность педагогов к оздоровительно-корригирующей деятельности в связи с учебной работой обучающихся с компьютером; алгоритм управления оздоровительно-корригирующей деятельностью педагогов в связи с учебной работой обучающихся с компьютером. 
В современных исследованиях неоднократно указывалось на необходимость привлечения внимания педагогов к проблеме безопасного использования компьютера обучающимися. Доказано, что работа с компьютером сопровождается воздействием на здоровье пользователя ряда негативных факторов: зрительное напряжение [1-6], психическое напряжение [7-12], физическое напряжение, связанное с длительным статическим напряжением мышц пользователя персонального компьютера [4; 6; 13-16]. Учителя не всегда владеют необходимыми компетенциями в сфере безопасного использования информационнокоммуникационных технологий (ИКТ) в обучении. С целью восполнения этого пробела нами был разработан алгоритм управления оздоровительно-корригирующей деятельностью педагогов в связи с учебной работой обучающихся с компьютером.

Под оздоровительно-корригирующей деятельностью педагогов в связи учебной работой обучающихся с компьютером мы понимаем часть педагогического процесса, ориентированного на диагностику, профилактику и коррекцию нарушений в состоянии здоровья обучающихся, связанных с негативным влиянием учебной работы с компьютером. Если говорить о составе оздоровительно-корригирующей деятельности, то, очевидно, его необходимо определять на основе положений общей теории деятельности. Учитывая это, в составе любой деятельности можно выделить субъект, объект, средства, процесс, результат, среду, условия [17, с. 8].

Субъектом оздоровительно-корригирующей деятельности является тот, кто осуществляет постановку цели, задач, выбирает методы, средства, формы организации для преобразования объекта. В качестве субъекта может выступать индивид (учитель информатики, учитель-предметник, родитель, обучающийся). Субъектом может быть группа людей (семья, педагогический коллектив школы и др.), а также социальные институты, представляющие государство.

Объекты оздоровительно-корригирующей деятельности можно рассматривать на нескольких уровнях. На первом уровне объектом оздоровительнокорригирующей деятельности могут выступать соответствующие знания, потребности, способности и пр. На втором уровне мы можем выделить конкретные характеристики каждого из объектов первого уровня, например, знания о негативном влиянии на здоровье пользователя длительной статической нагрузки и т.п.

Средствами оздоровительно-корригирующей деятельности являются прежде всего ее методы, технологии, формы организации, а также информация по вопросам здоровьеобеспечения обучающихся, оздоровительная гимнастика, гигиенические факторы.

Под процессом реализации оздоровительно-корригирующей деятельности мы подразумеваем взаимодействие субъекта и объекта и распределение средств в пространстве и времени.

Результат представляет собой целесообразные изменения показателей объекта, на которые оказывает влияние субъект с помощью выбранных средств и ориентации в определенных направлениях в процессе оздоровительно-корригирующей деятельности.
Среда представляет собой компонент оздоровительно-корригирующей деятельности и характеризуется участием в ней других систем (гигиенических, социальных, семейных и пр.).

В качестве условий успешной реализации оздоровительно-корригирующей деятельности необходимо выделить меру участия в ней других систем (управленческих, образовательных, социальных, экономических, экологических и др.).

Управление оздоровительно-корригирующей деятельностью педагогов в связи с учебной работой обучаюшихся с компьютером представляет собой процесс разработки и реализации педагогом системы действий на основе соответствующего алгоритма. Согласно общенаучным представлениям, функциями управления любой деятельностью, в том числе и оздоровительно-корригирующей, являются: проектирование, организация, регулирование, контроль и учет [17, с. 134-137]. В табл. 1 представлен алгоритм управления оздоровительно-корригирующей деятельностью педагогов, в котором ее этапы распределены соответственно функциям управления. Для его создания мы воспользовались технологическим алгоритмом действий, предложенным А.В. Фомичевым [18, с. 112-114].

1 этап. Проектирование - распределение целей и средств в пространстве (последовательность) и времени (продолжсительность) [17; 19; 20].

На первом этапе 1.1 педагог осуществляет диагностику обучающихся и их родителей, проводит анализ полученных данных, выделяет и конкретизирует объект проектирования. Под диагностикой понимается комплекс мероприятий, направленных на качественную и количественную оценку состояния здоровья обучающихся при использовании ИКТ. Для проведения диагностики можно воспользоваться анкетами, предложенными Н.К. Смирновым, по ориентировочной оценке состояния здоровья обучающихся в школе для обучающихся и их родителей (тестанкета для самооценки школьниками факторов риска ухудшения здоровья; тест-анкета для ориентировочной оценки риска нарушений зрения (для родителей); тест-анкета для ориентировочной оценки риска сколиоза и других нарушений осанки (для родителей)), а также тестами на интернет-зависимость (С.А. Кулаков; Кимберли Янг). Важную информацию могут дать и результаты медицинского осмотра учащихся класса.

В качестве объекта проектирования могут выступать следующие факторы: зрительное напряжение, физическое напряжение, связанное с длительной статической нагрузкой мышц пользователя персонального компьютера, психическое напряжение. В зависимости от преобладания того или иного фактора учитель выбирает соответствующий способ решения выявленных проблем. Так, при получении данных о высоком риске нарушений зрения в классе педагогу целесообразно спроектировать здоровьеобеспечивающую деятельность таким образом, чтобы обеспечить сохранение зрения обучающихся на имеющемся уровне. А при выявлении в классе нескольких детей с игровой или интернет-зависимостью - сделать акцент на системной работе в указанном направлении. 
Следующий пункт 1.2 - формулировка цели оздоровительно-корригирующей деятельности педагога на основе выявленных противоречий. Скажем, при выраженном нарушении зрения у многих учащихся в классе следует поставить цель: формирование готовности обучающихся, их родителей и учителей к сохранению и укреплению зрения. Пункт 1.3 представляет собой конкретизацию цели в виде задач, которые можно сформулировать следующим образом: а) формирование знаний о негативном влиянии на зрение длительной работы с персональным компьютером (ПК), а также о способах профилактики и коррекции нарушений зрения у всех участников образовательных отношений; б) формирование умений использовать полученные знания на практике; в) мотивация обучающихся, родителей, педагогов к ведению здорового образа жизни, заботе о своем зрении.

Сроки реализации оздоровительно-корригирующей деятельности (пункт 1.4) выбираются в зависимости от специфики ее осуществления и целевых установок. Поскольку такая деятельность требует тщательной подготовки учителя, видимо, стоит запланировать ее реализацию минимум на 1 год. На протяжении всего периода необходим мониторинг эффективности реализуемой педагогом системы действий.

Пункты 1.5-1.7 предполагают составление плана проекта, представляющего собой комплекс последовательно реализуемых шагов по решению поставленных задач; подбор необходимых средств и определение форм их реализации. В нашем примере это могут быть следующие действия.

1) Выступление педагога на ближайшем педагогическом совете образовательной организации с обсуждением негативных факторов, влияющих на здоровье пользователя ПК, представлением аналитики полученных данных по состоянию здоровья обучающихся его класса и примерного плана решения выявленных проблем. Привлечение к оздоровительной работе учителей-предметников, врача, психолога, учителей информатики и физической культуры; возможная коррекция планируемых действий.

2) Разработка педагогом (совместно с учителем физической культуры и врачом) оздоровительнокорригирующих модулей с учетом возрастных, индивидуальных, психологических особенностей школьников.

3) Подготовка технологии формирования у обучающихся навыков использования предложенных модулей (подбор методов, форм организации деятельности школьников).

4) Подготовка проектного задания для учащихся по выявленной проблеме.

5) Подготовка диагностических (анкеты, опросники) и прочих материалов (контролирующие листы для наблюдения за деятельностью детей с ПК, презентации о негативных факторах и правилах безопасной работы с компьютером, памятки (буклеты) с правилами организации рабочего места и т.п.) для организации просветительской работы с родителями обучающихся.
Пункт 1.8 представляет собой выбор педагогом видов контроля, технологии и сроков его проведения. На наш взгляд, целесообразно использовать все виды контроля: текущий, рубежный, итоговый - для обеспечения наибольшей эффективности реализуемых педагогом действий. По срокам: необходимо провести анкетирование обучающихся и родителей до начала реализации педагогом оздоровительнокорригирующей деятельности (то есть в начале учебного года), во время реализации проекта (на каждом этапе) и по его окончании.

2 этап. Организачия представляет собой упорядочение действий в пространстве и времени [17, c. 135].

Следующий шаг 2.1 в управлении педагогом оздоровительно-корригирующей деятельностью заключается в выявлении объекта организации. Логично, что в его качестве в нашем случае также будет выступать выраженное нарушение зрения у обучающихся класса. Пункт 2.2 представляет собой выявление условий организации здоровьеобеспечивающей деятельности: нормативно-правовых, кадровых, материально-технических, научно-методических и пр. На основании предыдущего пункта педагог конкретизирует требования и ограничения по реализации оздоровительно-корригирующей деятельности (пункт 2.3).

Затем осуществляется структуризация содержания организации деятельности - прорабатывается схема взаимодействия всех участников образовательных отношений (пункт 2.4). Руководствуясь нормативно-правовыми документами, учитывая запросы родителей, учитель, по сути, находится в субординационных отношениях (подчинения) с органами управления образованием и дирекцией школы и в координационных отношениях (взаимодействия) с другими педагогами, обучающимися и их родителями. Выбор, конкретизация способов, средств, методов организации педагогом и последующая реализация оздоровительно-корригирующей деятельности осуществляются на следующем этапе (2.5). Здесь целесообразно воспользоваться планом проекта реализации деятельности здоровьеобеспечения, составленным учителем в пунктах 1.5-1.7.

3 этап. Регулирование - субординация, координациия, коррекиия действий [17, с. 135].

Очевидно, что реализация педагогом системы оздоровительных воздействий может сопровождается некоторыми сбоями, отклонениями, требующими урегулирования. В этом случае учителю необходимо определить причины их появления (пункт 3.1). Сигналом к этому может послужить, например, дальнейшее ухудшение зрения обучающихся. Диагностика (опрос, беседы, индивидуальная работа с учениками, родителями, учителями) будет способствовать выяснению предмета регулирования (пункт 3.2). Это может быть несоблюдение школьниками, родителями, педагогами требований техники безопасной работы с компьютером; неправильно подобранные технологии реализации оздоровительно-корригирующей деятельности, отсутствие мотивации на здоровьеобеспечивающую деятельность у участников образовательных отношений и пр. На следующем этапе 3.3 совершается подбор наиболее оптимальных 
средств и методов регулирования. Например, при выявлении отсутствия контроля со стороны родителей длительности времяпрепровождения ребенка за компьютером дома уместна индивидуальная беседа, консультация врача, психолога. При выявлении неэффективности применяемых оздоровительно-корригирующих модулей - их коррекция совместно с врачом и учителем физической культуры. Таким образом, целью регулирования становится коррекция отношений участников образовательных отношений, направленная на устранение возникающих проблем.

4 этап. Контроль и учет - сличение цели и результата, фиксация и определение меры в пространстве и времени [17, с. 136-137].

На каждом этапе и по окончании реализации оздоровительно-корригирующей деятельности педагогом проводится измерение показателей (пункт 4.1), позволяющее провести анализ эффективности реализуемых воздействий, а также оценить динамику их изменения. Важным моментом является рефлексив- ный анализ обучающимися, родителями, учителями собственной деятельности и результатов взаимодействия участников процесса здоровьеобеспечения. В нашем примере сохранение остроты зрения детей в классе на заданном уровне - это уже показатель продуктивной работы педагогов, обучающихся и их родителей. Повышение информационного, операционального, мотивационного уровней готовности участников образовательных отношений к здоровьеобеспечивающей деятельности в области сохранения зрения - также продуктивный показатель.

Вместе с тем, может быть выявлено несоответствие полученного результата поставленной цели и задачам (пункт 4.2). В этом случае педагог изменяет содержание деятельности управления. Например, при отсутствии положительных изменений в состоянии здоровья обучающихся он осуществляет реструктуризацию - изменяет состав компонентов деятельности управления, последовательность их реализации.

Таблица 1 - Алгоритм управления оздоровительно-корригирующей деятельностью педагогов и его реализация

\begin{tabular}{|c|c|c|}
\hline № & $\begin{array}{c}\text { Этапы оздоровительно-корригирующей деятельности, } \\
\text { соответственно функциям управления }\end{array}$ & Ожидаемый результат \\
\hline 1 & \multicolumn{2}{|l|}{ Проектирование } \\
\hline 1.1 & $\begin{array}{l}\text { Изучение результатов диагностики состояния здоровья обуча- } \\
\text { ющихся, анкетирования родителей, педагогов. Выделение объ- } \\
\text { екта проектирования оздоровительно-корригирующей деятель- } \\
\text { ности на основе результатов диагностики }\end{array}$ & $\begin{array}{l}\text { Конкретизация объекта проектирова- } \\
\text { ния }\end{array}$ \\
\hline 1.2 & $\begin{array}{l}\text { Обобщение, сравнение, отбор наиболее значимой информации; } \\
\text { формулировка цели проекта, анализ возможностей ее достиже- } \\
\text { ния }\end{array}$ & $\begin{array}{l}\text { Постановка цели осуществления } \\
\text { оздоровительно-корригирующей дея- } \\
\text { тельности } \\
\end{array}$ \\
\hline 1.3 & Определение возможного состава задач проектирования & Конкретизация задач проектирования \\
\hline 1.4 & $\begin{array}{l}\text { Определение сроков реализации оздоровительно- } \\
\text { корригирующей деятельности }\end{array}$ & $\begin{array}{l}\text { Сроки реализации оздоровительно- } \\
\text { корригирующей деятельности }\end{array}$ \\
\hline 1.5 & $\begin{array}{l}\text { Составление плана действий, формулировка желаемого резуль- } \\
\text { тата }\end{array}$ & $\begin{array}{l}\text { План реализации проекта (комплекс } \\
\text { последовательно реализуемых шагов } \\
\text { по решению поставленных задач) }\end{array}$ \\
\hline 1.6 & $\begin{array}{l}\text { Определение структуры, обеспечивающей проектирование, по- } \\
\text { иск целесообразных средств }\end{array}$ & Средства для реализации проекта \\
\hline 1.7 & $\begin{array}{l}\text { Выбор средств оздоровительно-корригирующей деятельности, } \\
\text { форм их реализации, системы их использования }\end{array}$ & $\begin{array}{l}\text { Уточнение и обоснование средств, } \\
\text { форм их реализации }\end{array}$ \\
\hline 1.8 & $\begin{array}{l}\text { Выбор видов контроля (текущий, рубежный, итоговый), разра- } \\
\text { ботка технологии контроля, уточнение сроков его проведения }\end{array}$ & Оценка результатов контроля \\
\hline 2 & \multicolumn{2}{|l|}{ Организация } \\
\hline 2.1 & $\begin{array}{l}\text { Выявление объекта организации оздоровительно- } \\
\text { корригирующей деятельности }\end{array}$ & $\begin{array}{l}\text { Объект организации оздоровительно- } \\
\text { корригирующей деятельности }\end{array}$ \\
\hline 2.2 & $\begin{array}{l}\text { Выявление возможностей и условий организации оздоровитель- } \\
\text { но-корригирующей деятельности }\end{array}$ & $\begin{array}{l}\text { Соотнесение возможностей и усло- } \\
\text { вий организации оздоровительно- } \\
\text { корригирующей деятельности }\end{array}$ \\
\hline 2.3 & $\begin{array}{l}\text { Определение требований и ограничений по организации оздо- } \\
\text { ровительно-корригирующей деятельности }\end{array}$ & $\begin{array}{l}\text { Конкретизация требований и ограни- } \\
\text { чений по организации оздоровитель- } \\
\text { но-корригирующей деятельности } \\
\end{array}$ \\
\hline 2.4 & $\begin{array}{l}\text { Определение способов структуризации содержания организации } \\
\text { оздоровительно-корригирующей деятельности }\end{array}$ & $\begin{array}{l}\text { Структура содержания организации } \\
\text { оздоровительно-корригирующей дея- } \\
\text { тельности }\end{array}$ \\
\hline 2.5 & Выбор способов, средств, методов организации & $\begin{array}{l}\text { Конкретизация способов, средств, } \\
\text { методов организации }\end{array}$ \\
\hline
\end{tabular}




\begin{tabular}{|c|c|c|}
\hline 3 & \multicolumn{2}{|l|}{ Регулирование } \\
\hline 3.1 & $\begin{array}{l}\text { Диагностика отклонений в результатах реализации оздорови- } \\
\text { тельно-корригирующей деятельности }\end{array}$ & $\begin{array}{l}\text { Выявление причин появления откло- } \\
\text { нений }\end{array}$ \\
\hline 3.2 & Определение предмета регулирования & Предмет регулирования \\
\hline 3.3 & Выбор средств и методов регулирования & $\begin{array}{l}\text { Оптимизация средств и методов ре- } \\
\text { гулирования }\end{array}$ \\
\hline 3.4 & Выбор направлений субординации, координации, коррекции & $\begin{array}{l}\text { Субординация (соответствие требо- } \\
\text { ваниям), координация (взаимодей- } \\
\text { ствие), коррекция (воздействие) }\end{array}$ \\
\hline 4 & \multicolumn{2}{|l|}{ Контроль и учет } \\
\hline 4.1 & $\begin{array}{l}\text { Осуществление этапного и итогового контроля, рефлексия, ана- } \\
\text { лиз результатов реализации проекта }\end{array}$ & $\begin{array}{l}\text { Оценка динамики изменения } \\
\text { показателей }\end{array}$ \\
\hline 4.2 & $\begin{array}{l}\text { Коррекция содержания управления оздоровительно- } \\
\text { корригирующей деятельностью для дальнейшей реализации }\end{array}$ & $\begin{array}{l}\text { Изменение содержания деятельности } \\
\text { управления: состава компонентов, } \\
\text { последовательности их реализации }\end{array}$ \\
\hline
\end{tabular}

Таким образом, использование предложенного в данной статье алгоритма управления оздоровительно-корригирующей деятельностью педагогов в связи с учебной работой обучающихся с компьютером будет способствовать формированию у участников образовательных отношений готовности к такой деятельности и, в целом, сохранению здоровья подрастающего поколения.

\section{СПИСОК ЛИТЕРАТУРЫ:}

1. Кучма В.Р. Гигиеническая безопасность использования компьютеров в обучении детей и подростков / под ред. В.Р. Кучмы (Работаем по новым стандартам). М.: Просвещение, 2013. С. 38-39.

2. Махмадов Ш.К. Санитарно-гигиеническая характеристика условий пребывания школьников в компьютерных классах и их влияние на орган зрения: автореф. дис. ... канд. пед. наук. Душанбе, 2012. C. $12-14$.

3. Степанова М.И. Гигиенические основы организации начального обучения в современной школе: дис. ... д-ра пед. наук. М., 2003. С. 165-166.

4. Долодаренко А.Г. Проспективное исследование влияния занятий за компьютером на функциональное состояние и физическое развитие детей среднего школьного возраста: дис. ... канд. пед. наук. Казань, 2006. C. 26-38.

5. Лихачевская О.С. Как сохранить зрение при работе на компьютере. М.: Эксмо, 2010. С. 8-10.

6. Экономова Т.П. Особенности физического развития и метаболического статуса школьников пользователей персонального компьютера: дис. ... канд. пед. наук. Архангельск. 2003. С. 85-95.

7. Солдатова Г.В., Зотова Е.Ю., Чекалина А.И., Гостимская О.С. Пойманные одной сетью: социально-психологическое исследование представлений детей и взрослых об интернете / под ред. Г.В. Солдатовой. М., 2011. С. 30-37.

8. Коркина А.Ю. Критерии психологической оценки компьютерных игр и развивающих компьютерных программ // Педагогическая наука и образование. 2008. № 3. С. 20-28.

9. Запорожец А.В. Педагогическая профилактика аддиктивного поведения школьников в сфере информационно-коммуникационных технологий: дис. ... канд. пед. наук. Челябинск, 2010. С. 15-28.
10. Роберт И.В. Педагогико-эргономическая оценка средств информатизации и коммуникации, используемых в образовании // Вопросы современной педиатрии. 2006. Т. 5, № 5. С. 64-67.

11. Жукова М.В. Профилактика зависимости от компьютерных игр у младших школьников // Современная высшая школа: инновационный аспект. 2011. № 1. C. 69-75.

12. Громова Н.Н. Адаптивные возможности и эндокринный статус школьников, систематически занимающихся на компьютере: дис. ... канд. пед. наук. Ставрополь, 2006. С. 52-80.

13. Шуленина Н.С. Морфофункциональное и психофизиологическое состояние обучающихся при углубленном использовании компьютерных технологий в учебном процессе: дис. ... канд. пед. наук. Новосибирск, 2002. С. 110-120.

14. Глушкова Е.К., Барсукова Н.К., Сазанюк 3.И., Сорокина Т.Н., Степанова М.И. Воздействие учебных занятий с применением компьютера на работоспособность и самочувствие обучающихся старших классов // Гигиена и санитария. 1990. № 12. С. 50-53.

15. Глушкова Е.К., Барсукова Н.К., Белявская В.И., Воронова Б.3. и др. Гигиенические проблемы применения компьютеров в учебном процессе средней общеобразовательной школы // Гигиена и санитария. 1988. № 6. C. 19-22.

16. Дьячкова М.Г., Мордовский Э.А. Воздействие компьютерных технологий на здоровый образ жизни подрастающего поколения // Экология человека. 2012. № 5. C. 14-19.

17. Чичикин В.Т. Структура и регуляция профессиональной готовности педагога физической культуры: монография. Н. Новгород: Нижегородский институт развития образования, 2011. 256 с.

18. Фомичев А.В. Готовность педагога физической культуры к деятельности самообразования: монография. Н. Новгород: Нижегородский институт развития образования, 2015. $171 \mathrm{c}$.

19. Профессиональная педагогика: учебник для студентов, обучающихся по педагогическим специальностям и направлениям / под ред. С.Я. Батышева, А.М. Новикова. Изд. 3-е, переработанное. М.: Из-во ЭГВЕС, 2009. С. 289-291.

20. Бондарев П.Б., Курочкина В.Е. Проектирование в профессиональной деятельности // Школьные технологии. 2004. № 6. С. 113-123. 


\section{TEACHERS' HEALTH-CORRECTIVE ACTIVITY MANAGEMENT IN CONNECTION WITH STUDENTS' EDUCATIONAL WORK WITH COMPUTERS}

(C) 2017

Shcherbakova Natalia Borisovna, senior lecturer of Distance Learning Center Nizhny Novgorod Institute of the Education Development (Nizhny Novgorod, Russian Federation)

Abstract. The author of the paper pays attention to the problem of safe computer use by students. Schoolchildren's work with computers has such negative factors as: eye strain, mental stress, physical stress associated with prolonged static muscles tension of a personal computer user. That is why it is so important to train teachers for health-corrective activities with students who work with a computer. In this paper the author proposes to consider the algorithm of teachers' health-corrective activity management in connection with students' educational work with computers. The author notes the following components of teacher's health-corrective activity: subject, object, means, process, result, environment, conditions. The author defines management of teachers' health-corrective activity. The paper contains an algorithm of teachers' health-supporting activity management; the stages of this activity are defined in accordance with the management functions: designing, organization, regulation, control and accounting.

Keywords: students' health; health-corrective activity; teachers' readiness; student's work; computer; algorithm; health-supporting activity. 